\title{
A. Cron, Mémoires féminins de la fin du XVII siècle à la période révolutionnaire. Enquête sur la constitution d'un genre et d'une identité
}

\section{Laura Rescia}

\section{OpenEdition}

\section{Journals}

\section{Edizione digitale}

URL: http://journals.openedition.org/studifrancesi/10563

DOI: 10.4000/studifrancesi. 10563

ISSN: 2421-5856

\section{Editore}

Rosenberg \& Sellier

\section{Edizione cartacea}

Data di pubblicazione: 1 décembre 2017

Paginazione: $547-548$

ISSN: 0039-2944

\section{Notizia bibliografica digitale}

Laura Rescia, «A. Cron, Mémoires féminins de la fin du xvı" siècle à la période révolutionnaire. Enquête sur la constitution d'un genre et d'une identité», Studi Francesi [Online], 183 (LXI | III) | 2017, online dal 01 février 2018, consultato il 21 janvier 2021. URL: http://journals.openedition.org/studifrancesi/10563 ; DOI: https://doi.org/10.4000/studifrancesi.10563

Questo documento è stato generato automaticamente il 21 janvier 2021.

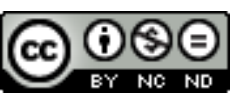

Studi Francesi è distribuita con Licenza Creative Commons Attribuzione - Non commerciale - Non opere derivate 4.0 Internazionale. 


\title{
A. Cron, Mémoires féminins de la fin du XVII siècle à la période révolutionnaire. Enquête sur la constitution d'un genre et d'une identité
}

\author{
Laura Rescia
}

\section{NOTIZIA}

ADÉLAÏDE CRON, Mémoires féminins de la fin du XVII siècle à la période révolutionnaire. Enquête sur la constitution d'un genre et d'une identité, Paris, Presses Sorbonne nouvelle, 2016, 286 pp.

1 All'indomani della Fronda, a partire dagli anni Settanta del xvii secolo e per tutto il secolo successivo, la memorialistica femminile subisce una notevole riduzione rispetto agli anni precedenti: è il momento in cui il ruolo politico delle donne sembra declinare, e il genere ricentrarsi sugli aspetti della vita privata femminile, ma altresì sui percorsi personali e sulla ridefinizione della propria identità. La memorialistica assume allora una dimensione autobiografica prevalente: la scrittura di questi mémoires si orienta nell'epoca considerata verso la composizione di testi ibridi, dinamici, le cui caratteristiche sembrano sfuggire a un tentativo classificatorio. Il volume presenta i risultati di una tesi di dottorato che assume come corpus una quindicina di testi, scritti tra il 1670 e gli anni della Rivoluzione, anche se spesso pubblicati a posteriori, interrogandoli sotto diversi profili. L'A. affronta immediatamente il problema della cosiddetta scrittura "femminile" e, riprendendo gli assunti del testo fondatore di Béatrice Didier L'écriture-femme, sottolinea come non si sia orientata alla ricerca di una specificità tematica o stilistica, impossibile da distinguere in base all'appartenenza sessuale. L'unica costante può essere identificata nella predisposizione a una forma di scrittura come i petits genres mondani, e nella predilezione ad affrontare determinate 
tematiche, che non risultano tuttavia uniche né esclusive della scrittura femminile. Viene poi definita una periodizzazione, distinguendo una prima fase, compresa tra il 1675 e il 1720, contraddistinta da due sottogruppi di testi: quelli delle donne "scandalose", la cui vita privata viene narrata nell'apparente intento di riabilitare la propria reputazione, e quelli delle donne protestanti e/o erranti, accomunate da un destino esemplare e da un certo grado di insofferenza alla sottomissione. La seconda fase, distanziata di una trentina d'anni dalla precedente, e che si chiude con il 1793, sembra contraddistinta da una forte presenza di mémoires-romans, che sembrano risentire dell'influenza rousseauiana. L'A. passa in rassegna le biografie delle autrici, piuttosto distanti dal modello della dama aristocratica dei Salons secenteschi: le loro vite, suggerisce Cron, sembrano caratterizzate da un "disallineamento" tra identità sociale e reputazione, segnalato dalla consapevolezza di possedere un'individualità poco conforme agli stereotipi della femminilità dell'epoca. Attingendo a influenze e tradizioni diverse, queste donne dichiarano la loro volontà di scrivere pur senza sentire di appartenere alla categoria delle intellettuali. La loro elaborazione di rappresentazioni inedite dell'identità femminile mescola sottomissione e contestazione dei ruoli tradizionali, elaborando una concezione talvolta ambigua del loro ruolo, veicolata da testi di elevata complessità formale (in particolare, dai dispositivi della doppia enunciazione, così frequenti nella scrittura libertina). Il saggio, articolato in tre parti, dedicate rispettivamente alla introduzione e definizione della metodologia della ricerca, all'indagine sui topos e sui contenuti dei mémoires, e infine agli aspetti formali ed enunciativi dei testi, è completato da una buona bibliografia. 